\title{
The Development of Laboratory Safety Questionnaire for Middle School Science Teachers
}

\author{
Simge Akpullukcu ${ }^{1 *}$, Bulent Cavas ${ }^{2}$ \\ ${ }^{1}$ Vali Kadir Uysal Middle School, Aydin-Turkey, ${ }^{2}$ Department of Science Education, Faculty of Education, Dokuz Eylul University, Izmir-Turkey
}

*Corresponding Author: bulentcavas@gmail.com

\section{ABSTRACT}

The purpose of this paper is to develop a "valid and reliable laboratory safety questionnaire" which could be used to identify science teachers' understanding about laboratory safety issues during their science laboratory activities. The questionnaire was developed from a literature review and prior instruments developed on laboratory safety issues. To address content validity, the questionnaire was examined by experts from the field of science education. The questionnaire consists of 36 Likert-type items related to chemicals, usage of glassware equipment, fire and electrical control, personal protection, biological hazards, and emergency. The study was carried out with 127 teachers who have experience in science laboratories and work in middle schools in Turkey. The instrument was found to be internally consistent with high reliability scores. Significance value shows that the data come from a multivariate normal distribution and are suitable for factor analysis. The factor analysis indicates that the items in the questionnaire accumulate around a single dimension named as safety issues. The results provide evidence that the instrument is valid for further implementation on a wider scale and in larger samples. The results of this study showed that the questionnaire has an appropriate scale to determine the middle school science teachers' understanding toward laboratory safety issues.

KEY WORDS: laboratory safety questionnaire; validity; reliability; middle school science teachers

\section{INTRODUCTION}

$O^{2}$ cience is a way of discovering and questioning life and how those things work today, how they worked in the past, and how they are likely to work in the future. The teachers of the future will not share with their students just empirical data but their own vision and way to critically understand the facts that are considered (Pavlova and Kouzov, 2016). In the educational area, science lessons provide students with the opportunities to undertake experiments. It is important that they follow the experimental process while engaged in these activities and use cognitive process skills.

A science teacher has to work continuously, be aware of current requirements, and take responsibility for every person in the classroom and laboratory. In this manner, safety issues have to be considered for all parts of each activity. In Turkey, middle school communities have become much more concerned about safety in science education.

Attention should be given to the safety aspects of each experimental design to improve safety factors. In schools, safety is compounded by the age of the students and the materials. Accidents have ranged from simple cuts to severe burns or serious damage. During an experiment in a laboratory, an explosion occurred in a school in Tunceli in 2013 resulting in two students and a teacher being injured ${ }^{1}$. Another accident

1 http://www.sabah.com.tr/Yasam/2013/02/13/okullaboratuvarindapatlama. involved a larger number of people. A primary school organized a spring festival at the end of the year in Kağıthane-İstanbul. As part of the activities, teachers and students collectively demonstrated an experiment in 2012. An explosion occurred injuring six students ${ }^{2}$. At a primary school in Hakkari, three students were injured due to an explosion during laboratory experiments in 2010. The class was working on an activity based on soap making. They used salt, water, oil, and alcohol when their mixture exploded ${ }^{3}$. Similarly, an explosion occurred during the experiment in the science laboratory of a private school in 2010. The teacher and five students were injured as a fire broke out after the explosion in the laboratory ${ }^{4}$. Finally, at the science laboratory of the Professional and Technical Education Center in Mardin, an explosion occurred at night in 2009. The test tubes exploded due to the effect of extreme heat $^{5}$. Due to accidents like those previously mentioned, it is apparent that there need to be some arrangements and educational interventions that can minimize such accidents.

Aydoğdu and Yardımc1 (2013) analyzed the news, which was placed in both local and national newspapers. According to their study, it was seen that the accidents related to the explosions of an experiment involving tubes, spirits, steel tubes

\footnotetext{
2 http://www.memurlar.net/haber/239274.

3 http://www.hakkarihabertv.com/deney-laboratuvarinda-patlama6514h.htm.

4 http://www.turkmedya.com/V1/Pg/detail/NewID/328972.

5 http://www.ogretmenlersitesi.com/haber/4491.
} 
and bulbs, diffusion of chemicals, gas rising, and breaking of mercury tubes. The reasons of these accidents were as follows: Absence or misconceptions of knowledge of characteristics of chemicals; not knowing how to intervene when chemicals were spilled; carelessness during experiments; students' use of experimental equipment without teachers' control; and not knowing or having a professional response toward experimental hazards.

It is important to create an environment in which appropriate laboratory behavior is maintained. An accident happens suddenly, and the teacher should be well prepared for such cases. Planning the activities carefully, providing careful directions before allowing students to attempt independent projects, protecting the health welfare and safety of their students, reporting all hazardous conditions, and being present in the laboratory to ensure adequate safety supervision are some of the necessities during the lessons.

Interestingly, it has been found that studies that focus on science laboratories in the educational area mainly deal with the materials, methods, and technics. Unfortunately, there has been limited attention to safety issues. Therefore, it is important to have an understanding about science teachers' knowledge and understanding about laboratory safety responsibilities. As teachers responsibilities include not only safety related with the science laboratories but also for every chemical or material they bring into or accept in their classroom. They must know what each is, what it can do, and how it should be stored. Teachers should be informed about all safety issues which include biological and animal hazards, blood-borne pathogens, chemicals, electrical safety, handling glassware, fire control, labelling, and eye and face protection.

It is important to make teachers of science more aware of potential dangers in the teaching of science and the responsibilities in maintaining classroom safety. The reasonable teacher must be able to anticipate the common ordinary events and even the extraordinary ones, in some cases (Downs and Gerlovich, 1983).

The aim of this study was to develop a laboratory safety questionnaire to evaluate science teachers' understanding about laboratory safety issues.

\section{METHODOLOGY}

A Likert-type scale was used to develop this study's questionnaire to identify science teachers' understanding of laboratory safety issues. There are many advantages of using questionnaires for research. A large amount of information can be collected from a large number of people in a short period of time and in a relatively cost-effective way. Furthermore, questionnaires are important in terms of ensuring standardization for the answers (Balc1, 2007).

The object of the questionnaire was ascertaining the participating teachers' agreement with the scale items (Appendix Table 1). The questionnaire used a 4-point scale
Table 1: Pilot study distribution by gender with frequency and percentage

\begin{tabular}{lc}
\hline Gender & Frequency $\mathbf{n}(\%)$ \\
\hline Female & $81(63.7)$ \\
Male & $46(36.3)$ \\
Total & $127(100)$ \\
\hline
\end{tabular}

ranging from "strongly agree" to "strongly disagree." Each response on the questionnaire was assigned with a numeric value between 4 and 1. A "neutral" answer was not included to have an exact and clear understanding (positive or negative) about their decisions.

Items of the questionnaire: Project reports, researches, and studies conducted on laboratory safety issues were examined. After generating a number of questions about safety procedures, the most representative of them have been compiled into a list of 37 .

Content validity: Content validity addresses the match between test questions and the content or individual area, which they are intended to assess. With regard to the validity of the questionnaire, five experts from the field of science education examined the questionnaire items. According to the suggestions and criticisms of the experts, the questionnaire items were edited. The pilot version of questionnaire was created.

Sample: Tabachnick and Fidell (2001) suggest that a smaller sample size should be sufficient if solutions have several high loading marker variables (above 0.80 ). According to Johanson and Brooks (2009), there is little discussion in the literature of how to determine appropriate sample sizes for these types of pilot studies. Treece and Treece (1982), referring to piloting an instrument, noted that, for a project with " 100 people as the sample, a pilot study participation of 10 individuals should be a reasonable number" (p. 176). For the process of developing the questionnaire, 127 participants were chosen from the middle school science teachers working in Aydın, Turkey.

\section{Demographic Characteristics of Sample \\ Gender}

The pilot study was carried out with 127 participants. According to Table 1,81 of the participants were female (63.7\%), and 46 of them were male (36.3\%). The distribution of gender is similar to the distribution of Turkish teachers as the gender of teachers during the 2013-2014 years were 64.8\% of female and $35.2 \%$ of male (TÜİK, 2014).

\section{Age}

The distribution by age range with frequency and percentage is shown in Table 2. The age range of 20-29 has the highest number with 57 participants (44.8\%), and the age range of 60 and over has the lowest number with only two participants $(1.6 \%)$.

\section{Graduation}

Table 3 shows the distribution by graduation degree with frequency and percentage. There were 111 (87.4\%) participants 
with an undergraduate degree, $11(8.7 \%)$ participants with a graduate degree, and 5 (3.9\%) with a postgraduate degree.

\section{Teaching experience}

Table 4 represents the distribution range of years of teaching experience with frequency and percentage. 49 participants have been working for 1-5 years; 23 for 6-10 years; 23 for $11-15$ years; 12 for $16-20$ years; and 20 for over 21 years.

\section{Field}

Table 5 shows the distribution field of study with frequency and percentage. 75 (59.1\%) of the participants studied general science; 15 (11.8\%) biology; 12 (9.4\%) chemistry; 6 (4.7\%) physics; and while 19 (15\%) of them studied mathematics, these teachers were still responsible for some laboratory activities.

\section{RESULTS}

\section{Exploratory Factor Analyses}

Factor analyses take a large set of variables and look for a way that the data may be "reduced" or summarized using a smaller set of factors or components. Exploratory factor analysis is often used in the early stages of research to gather information about (explore) the interrelationships among a set of variables (Pallant, 2005).

\begin{tabular}{lc}
\hline $\begin{array}{l}\text { Table 2: Pilot study distribution by range of age with } \\
\text { frequency and percentage }\end{array}$ \\
\hline Age range & Frequency $\mathbf{n}(\%)$ \\
\hline $20-29$ & $57(44.8)$ \\
$30-39$ & $42(33.1)$ \\
$40-49$ & $17(13.4)$ \\
$50-59$ & $9(7.1)$ \\
$60-+$ & $2(1.6)$ \\
Total & $127(100.0)$ \\
\hline
\end{tabular}

\begin{tabular}{lc}
\hline $\begin{array}{l}\text { Table 3: Pilot study distribution by graduation with } \\
\text { frequency and percentage }\end{array}$ \\
\hline Graduation degree & Frequency $\mathbf{n}(\%)$ \\
\hline Undergraduate & $111(87.4)$ \\
Graduate & $11(8.7)$ \\
Postgraduate & $5(3.9)$ \\
Total & $127(100.0)$ \\
\hline
\end{tabular}

Table 4: Pilot study distribution by years of teaching experience with frequency and percentage

\begin{tabular}{lc}
\hline Years of teaching experience & Frequency $\mathbf{n}(\%)$ \\
\hline $1-5$ & $49(38.6)$ \\
$6-10$ & $23(18.1)$ \\
$11-15$ & $23(18.1)$ \\
$16-20$ & $12(9.4)$ \\
21 & $20(15.7)$ \\
Total & $127(100.0)$ \\
\hline
\end{tabular}

Construct validity refers to the degree to which a test or other measure assesses the underlying theoretical construct it is supposed to measure. To determine the validity of the questionnaire, exploratory factor analysis was used on the data. Factor analysis attempts to bring intercorrelated variables together under more general, underlying variables. Factor analysis offers not only the possibility of gaining a clear view of the data but also the possibility of using the output in subsequent analyses (Field, 2000). In this process, descriptive statistics and the correlation matrix (with the coefficients, significance levels, determinant, Kaiser-Meyer-Olkin (KMO), and Bartlett's test of sphericity, inverse, reproduced matrix, and anti-image matrix) were obtained.

In SPSS, a convenient option is offered to check whether the sample is big enough: The KMO measure of sampling adequacy (KMO-test). The sample is adequate if the value of $\mathrm{KMO}$ is $>0.5$ (Field, 2000). The KMO index ranges from 0 to 1 , with 0.6 suggested as the minimum value for a good factor analysis (Tabachnick and Fidell, 2001). The value of KMO was calculated as 0.937 (Table 6). This value shows that the sample with 127 participants was adequate for the level of representation.

The intercorrelation can be checked using Bartlett's test of sphericity, which "tests the null hypothesis that the original correlation matrix is an identity matrix" (Field, 2000. p. 457).

The Bartlett's test of sphericity should be significant $(p<0.05)$ for the factor analysis to be considered appropriate (Pallant, 2005). Significance value is calculated 0.00 which is a $>0.05(p<0.05)$. The value shows that the data come from a multivariate normal distribution and are suitable for factor analysis.

\section{Determining the Factor Number}

It is needed to look in the total variance explained table (Table 7) and scree plot (Graph 1) to determine how many components meet this criterion.

\begin{tabular}{lc}
\hline $\begin{array}{l}\text { Table 5: Pilot study distribution by field with frequency } \\
\text { and percentage }\end{array}$ \\
\hline Field & Frequency $\mathbf{n}(\%)$ \\
\hline Science & $75(59.1)$ \\
Biology & $15(11.8)$ \\
Chemistry & $12(9.4)$ \\
Physics & $6(4.7)$ \\
Other (mathematics) & $19(15.0)$ \\
Total & $127(100.00)$ \\
\hline
\end{tabular}

\begin{tabular}{lc}
\hline Table 6: KMO and Bartlett's test & \\
\hline KMO measure of sampling adequacy & 0.937 \\
Bartlett's test of sphericity & \\
Approximate Chi-square & 4490.397 \\
df & 666 \\
Significant & 0.000 \\
\hline KMO: Kaiser-Meyer-Olkin
\end{tabular}

KMO: Kaiser-Meyer-Olkin 


\begin{tabular}{|c|c|c|c|c|c|c|}
\hline \multirow[t]{2}{*}{ Component } & \multicolumn{3}{|c|}{ Initial eigenvalues } & \multicolumn{3}{|c|}{ Extraction sums of squared loadings } \\
\hline & Total & $\%$ of variance & Cumulative \% & Total & $\%$ of variance & Cumulative \% \\
\hline 1 & 19.460 & 52.594 & 52.594 & 19.460 & 52.594 & 52.594 \\
\hline 2 & 2.642 & 7.139 & 59.733 & 2.642 & 7.139 & 59.733 \\
\hline 3 & 1.706 & 4.611 & 64.344 & 1.706 & 4.611 & 64.344 \\
\hline 4 & 1.313 & 3.550 & 67.894 & 1.313 & 3.550 & 67.894 \\
\hline 5 & 1.146 & 3.097 & 70.991 & 1.146 & 3.097 & 70.991 \\
\hline 6 & 1.015 & 2.744 & 73.734 & 1.015 & 2.744 & 73.734 \\
\hline 7 & 0.989 & 2.672 & 76.406 & & & \\
\hline 8 & 0.746 & 2.017 & 78.423 & & & \\
\hline 9 & 0.728 & 1.968 & 80.391 & & & \\
\hline 10 & 0.629 & 1.701 & 82.092 & & & \\
\hline 11 & 0.556 & 1.504 & 83.596 & & & \\
\hline 12 & 0.511 & 1.381 & 84.976 & & & \\
\hline 13 & 0.483 & 1.306 & 86.282 & & & \\
\hline 14 & 0.425 & 1.149 & 87.432 & & & \\
\hline 15 & 0.400 & 1.081 & 88.512 & & & \\
\hline 16 & 0.388 & 1.048 & 89.561 & & & \\
\hline 17 & 0.375 & 1.015 & 90.575 & & & \\
\hline 18 & 0.334 & 0.902 & 91.477 & & & \\
\hline 19 & 0.313 & 0.845 & 92.323 & & & \\
\hline 20 & 0.308 & 0.833 & 93.156 & & & \\
\hline 21 & 0.282 & 0.762 & 93.918 & & & \\
\hline 22 & 0.247 & 0.667 & 94.585 & & & \\
\hline 23 & 0.239 & 0.645 & 95.230 & & & \\
\hline 24 & 0.212 & 0.574 & 95.804 & & & \\
\hline 25 & 0.188 & 0.508 & 96.312 & & & \\
\hline 26 & 0.185 & 0.500 & 96.812 & & & \\
\hline 27 & 0.165 & 0.447 & 97.258 & & & \\
\hline 28 & 0.159 & 0.429 & 97.687 & & & \\
\hline 29 & 0.141 & 0.381 & 98.069 & & & \\
\hline 30 & 0.129 & 0.349 & 98.418 & & & \\
\hline 31 & 0.117 & 0.317 & 98.735 & & & \\
\hline 32 & 0.114 & 0.309 & 99.044 & & & \\
\hline 33 & 0.104 & 0.281 & 99.325 & & & \\
\hline 34 & 0.080 & 0.216 & 99.541 & & & \\
\hline 35 & 0.072 & 0.195 & 99.736 & & & \\
\hline 36 & 0.061 & 0.166 & 99.902 & & & \\
\hline 37 & 0.036 & 0.098 & 100.000 & & & \\
\hline
\end{tabular}

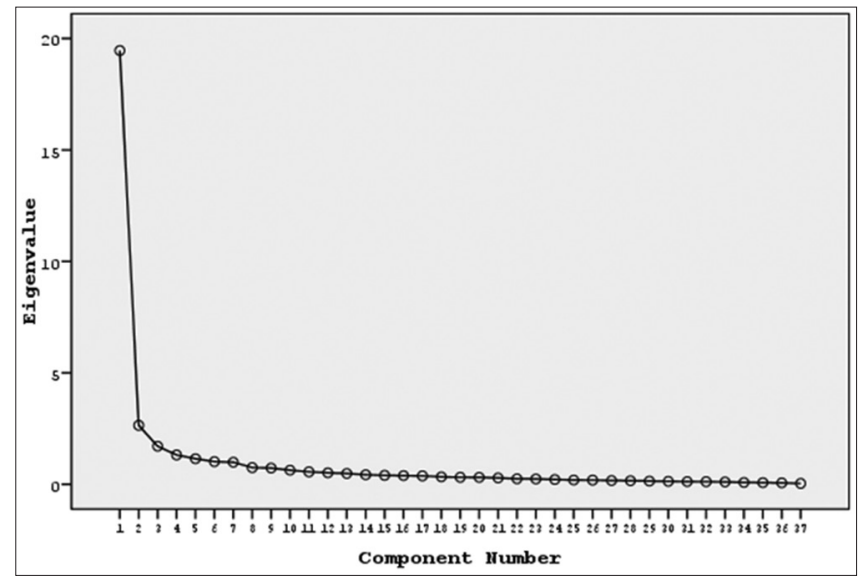

Graph 1: Scree plot
The eigenvalue of a factor represents the amount of the total variance explained by that factor which is called the Kaiser's criterion. Only the factors with an eigenvalue of 1.0 or more are retained for further investigation (Pallant, 2005).

In Table 7, the eigenvalues for each component are listed in the first set of columns. Only the first six components recorded eigenvalues above 1 (19.460, 2.642, 1.706, 1.313, 1.146, and 1.015). These six components explain a total of $73.734 \%$ of the variance. The total variance of the first component is $52.594 \%$ while the other five components have a smaller percentage of variance with contiguous values to each other. The questionnaire with single dimension is considered if the percentage of variance equals or is above 0.30 (Büyüköztürk, 2003). Therefore, it can be thought that the questionnaire has a 
single dimension. To strengthen the data, it is important to look at the scree plot. The scree test is one of the techniques that can be used to assist in the decision concerning the number of factors to retain. This involves plotting each of the eigenvalues of the factors and inspecting the plot to find a point at which the shape of the curve changes direction and becomes horizontal (Pallant, 2005).

According to Graph 1, there is quite a clear break between the first and second components. Component 1 explains or captures much more of the variance than the remaining components. From this plot, it is recommended to retain only one component. This relationship enabled the collapse of the 37 items into one factor. It indicates that the items in the questionnaire accumulate around a single dimension. After determining the number of factors, the analyses have to be repeated.

It is understood from Table 8 in component matrix ${ }^{a}$ that most of the items load quite strongly above 0.4 on the one component except item S24. The item 24 has a value of 0.316 , which is smaller than the criterion value. This supports the conclusion from the scree plot to retain only one factor for investigation. As a result, item S24 was removed and the analyses repeated. The component matrix ${ }^{\mathrm{b}}$ shows the results after removing S24. According to Table 8, it can be shown that there are not any other items with a value of less than the criterion value (0.4). Moreover, all the remaining items have a similar meaning which we called "safety issues" for this single dimension. The analysis process is complete. The latest analysis is taken into consideration with new values of

Table 8: Component matrixes of items

\begin{tabular}{|c|c|c|c|}
\hline Item No. & Item & $\begin{array}{c}\text { Component } \\
\text { matrix }^{b}\end{array}$ & $\begin{array}{c}\text { Component } \\
\text { matrix }^{a}\end{array}$ \\
\hline S27 & I know how to respond in case of a burn which occurs with contact to hot objects & 0.843 & 0.841 \\
\hline S17 & I know how to use first aid kits in laboratory & 0.830 & 0.830 \\
\hline $\mathrm{S} 10$ & I know how to use water system in laboratory & 0.823 & 0.823 \\
\hline $\mathrm{S} 23$ & I work with an inventory which has the identifications of all chemicals in the laboratory & 0.820 & 0.819 \\
\hline S9 & I know how to use electrical and lighting in laboratory & 0.818 & 0.817 \\
\hline $\mathrm{S} 2$ & I know precautions to be taken in case of a fire in laboratory & 0.817 & 0.816 \\
\hline $\mathrm{S} 28$ & I know what should be done if any chemicals splash to the eyes & 0.814 & 0.813 \\
\hline S26 & I know what should be done in case of bleeding & 0.807 & 0.804 \\
\hline S3 & I know precautions to be taken in case of spills and splashes of chemicals & 0.788 & 0.788 \\
\hline S1 & I always take care the laboratory is clean and tidy & 0.786 & 0.785 \\
\hline $\mathrm{S} 21$ & I know how to store and keep the liquid chemicals & 0.778 & 0.776 \\
\hline $\mathrm{S} 22$ & I know how to store chemicals which need to have special conditions & 0.775 & 0.774 \\
\hline S36 & I always take care about to put laboratory materials to the right places after using & 0.775 & 0.773 \\
\hline S33 & I never leave the laboratory before checking all electrical devices & 0.774 & 0.771 \\
\hline S34 & I never leave the laboratory before checking water system & 0.766 & 0.765 \\
\hline S35 & I labeled the remaining material and get stored in an appropriate manner after the activities & 0.761 & 0.761 \\
\hline S5 & I know the phone numbers to call in an emergency situation & 0.752 & 0.750 \\
\hline $\mathrm{S} 15$ & I know how to design the desks for the students in the laboratory & 0.747 & 0.746 \\
\hline S4 & I know which emergency kits have to be in a laboratory for using in case of an emergency situation & 0.746 & 0.745 \\
\hline S31 & I know how to intervene in the accident that occurred as a result of electric current & 0.726 & 0.725 \\
\hline $\mathrm{S} 32$ & I never leave the laboratory before checking the gas installations & 0.718 & 0.719 \\
\hline S37 & I get students to wash their hands and face with water after the activities & 0.716 & 0.715 \\
\hline $\mathrm{S} 13$ & I know how to use bucket of sand in case of a fire & 0.705 & 0.706 \\
\hline $\mathrm{S} 14$ & I know how to use fire blanket in case of a fire & 0.698 & 0.699 \\
\hline $\mathrm{S} 12$ & I know how to use fire extinguisher in case of a fire & 0.694 & 0.696 \\
\hline S19 & I always take care about the shelves are firmly attached to the wall & 0.691 & 0.695 \\
\hline S16 & I know the needs and uses of an emergency exit plan & 0.688 & 0.689 \\
\hline S8 & I know how to use the ventilation system & 0.676 & 0.677 \\
\hline $\mathrm{S} 20$ & I always take care all shelves have the protection sets in front sides & 0.661 & 0.664 \\
\hline $\mathrm{S} 30$ & I know how to intervene if need occurs with inhalation of chemicals & 0.641 & 0.643 \\
\hline S11 & I know how to use gas installations & 0.623 & 0.626 \\
\hline S18 & I know how to store and keep solid chemicals & 0.613 & 0.612 \\
\hline S6 & I have information about the health status of my students & 0.612 & 0.611 \\
\hline $\mathrm{S} 29$ & I know how to intervene if need occurs in case of ingestion of any chemicals & 0.602 & 0.603 \\
\hline $\mathrm{S} 25$ & I always wear apron during the activities in laboratory & 0.597 & 0.598 \\
\hline S7 & I know how should be the standards of an ideal laboratory for schools & 0.584 & 0.586 \\
\hline $\mathrm{S} 24$ & Removing item & - & 0.316 \\
\hline
\end{tabular}


KMO and Bartlett's test and the total variance explained as shown in Table 9.

After the 1 item was removed, the value of KMO was calculated as 0.94 (Table 9). This value shows that the sample with 127 participants is still adequate for the level of representation. Significance value was calculated at 0.00 which is $>0.05(p<0.05)$. The value shows that the data come

\begin{tabular}{lc}
\hline Table 9: KMO and Bartlett's test & \\
\hline KMO measure of sampling adequacy & 0.940 \\
Bartlett's test of Sphericity & \\
Approximate Chi-square & 4413.359 \\
df & 630 \\
Significant & 0.000 \\
\hline
\end{tabular}

KMO: Kaiser-Meyer-Olkin from a multivariate normal distribution and are suitable for factor analysis.

Table 10 lists the eigenvalues for each component. As shown, one component explains a total of $53.79 \%$ of the variance.

\section{Reliability}

To test the reliability of the questionnaire, Cronbach's alpha reliability coefficient value and item-total correlation of test score were examined. Cronbach's alpha is the most common measure of internal consistency. It is most commonly used when you have multiple Likert-type questions in a questionnaire that forms a scale, and you wish to determine if the scale is reliable.

Cronbach's alpha was 0.975 , which is good considering that 0.70 is the cutoff value for being acceptable (Kurnaz and

Table 10: Total variance explained

\begin{tabular}{|c|c|c|c|c|c|c|}
\hline \multirow[t]{2}{*}{ Component } & \multicolumn{3}{|c|}{ Initial eigenvalues } & \multicolumn{3}{|c|}{ Extraction sums of squared loadings } \\
\hline & Total & $\%$ of variance & Cumulative \% & Total & $\%$ of variance & Cumulative $\%$ \\
\hline 1 & 19.365 & 53.791 & 53.791 & 19.365 & 53.791 & 53.791 \\
\hline 2 & 2.604 & 7.234 & 61.025 & & & \\
\hline 3 & 1.586 & 4.405 & 65.430 & & & \\
\hline 4 & 1.304 & 3.621 & 69.052 & & & \\
\hline 5 & 1.029 & 2.858 & 71.910 & & & \\
\hline 6 & 1.005 & 2.790 & 74.700 & & & \\
\hline 7 & 0.813 & 2.260 & 76.960 & & & \\
\hline 8 & 0.741 & 2.059 & 79.019 & & & \\
\hline 9 & 0.721 & 2.003 & 81.022 & & & \\
\hline 10 & 0.603 & 1.675 & 82.697 & & & \\
\hline 11 & 0.533 & 1.480 & 84.177 & & & \\
\hline 12 & 0.484 & 1.344 & 85.521 & & & \\
\hline 13 & 0.428 & 1.190 & 86.711 & & & \\
\hline 14 & 0.410 & 1.140 & 87.851 & & & \\
\hline 15 & 0.393 & 1.091 & 88.942 & & & \\
\hline 16 & 0.385 & 1.068 & 90.010 & & & \\
\hline 17 & 0.338 & 0.939 & 90.948 & & & \\
\hline 18 & 0.328 & 0.910 & 91.858 & & & \\
\hline 19 & 0.313 & 0.869 & 92.727 & & & \\
\hline 20 & 0.285 & 0.792 & 93.518 & & & \\
\hline 21 & 0.272 & 0.756 & 94.275 & & & \\
\hline 22 & 0.243 & 0.675 & 94.950 & & & \\
\hline 23 & 0.213 & 0.591 & 95.541 & & & \\
\hline 24 & 0.203 & 0.564 & 96.105 & & & \\
\hline 25 & 0.188 & 0.522 & 96.627 & & & \\
\hline 26 & 0.180 & 0.500 & 97.127 & & & \\
\hline 27 & 0.159 & 0.441 & 97.568 & & & \\
\hline 28 & 0.148 & 0.411 & 97.979 & & & \\
\hline 29 & 0.132 & 0.368 & 98.347 & & & \\
\hline 30 & 0.120 & 0.333 & 98.680 & & & \\
\hline 31 & 0.114 & 0.317 & 98.997 & & & \\
\hline 32 & 0.105 & 0.291 & 99.288 & & & \\
\hline 33 & 0.083 & 0.229 & 99.518 & & & \\
\hline 34 & 0.076 & 0.210 & 99.728 & & & \\
\hline 35 & 0.061 & 0.170 & 99.898 & & & \\
\hline 36 & 0.037 & 0.102 & 100.000 & & & \\
\hline
\end{tabular}




\begin{tabular}{lc}
\hline Table 11: Statistics of reliability & \\
\hline Cronbach's Alpha & 0.975 \\
Number of items & 36 \\
\hline
\end{tabular}

\section{Table 12: Values for the last version of the questionnaire}

\begin{tabular}{lc} 
Total number of items & 37 \\
Number of deleted items & 1 \\
KMO test & 0.940 \\
Bartlett's test & 0.000 \\
Cronbach's alpha & 0.975 \\
\hline
\end{tabular}

KMO: Kaiser-Meyer-Olkin

Yiğit, 2010). The value shows that the data indicate a high level of internal consistency. Item-total correlation of test scores explains the relationship between item scores and the total score of the test substances. High and positive correlation of item-total test score indicates internal consistency. The study's questionnaire has a good internal consistency, with a Cronbach's alpha coefficient reported of 0.975 (Table 11).

To have confidence in the results of a study, one must be assured that the questionnaire consistently measures what it purports to measure when properly administered. The questionnaire must be both valid and reliable (Greco et al., 1987). According to Table 12, the Cronbach's alpha coefficient, which in this case is 0.975 , can be considered reliable with our sample. 1 item was removed with an absolute value lower than 0.4 (which explain around $16 \%$ of variance) in the last version of the questionnaire. In its final form, the questionnaire has 36 items which collapse into one factor. The underlying structure identified as "safety issues." In this study, it can be understood that all items can be grouped in one single dimension. There are some other similar studies of questionnaires results with single dimension (Engs, 1996; Turanli et al., 2008; Doğan, 2010).

\section{CONCLUSION}

The study's laboratory safety questionnaire can be helpful for preparing safer science lessons. Being prepared means planning, the science activities carefully and providing complete directions before allowing students to attempt independent projects. It means protecting the health welfare and safety of the students and reporting all hazardous conditions. Moreover, it means being present in the laboratory to ensure adequate safety supervision.

The questionnaire can be used for improving awareness about accidents at schools. Unfortunately, accidents have been reported to be occurring too frequently in Turkish middle school science laboratories. In addition, it is likely that there are other accidents that are not reported. Faced with these accidents, it is important to know whether or not the laboratory safety precautions and practices in Turkish schools are adequate. It is critical to make science teachers more aware of both the potential dangers in science education and their responsibilities in maintaining classroom safety.
Using the questionnaire, it can be understood the needs of safety courses at schools. Making an effective safety course for science teachers can help to create a safer and healthier environment not only inside the laboratories and classrooms but also in the rest of the students' and teachers' lives. Safety is a key to ensuring the success of our next generation of innovators in science, technology, engineering, and mathematics. It is a key to having citizens and parents who care about health, safety, and the environment. Moreover, it is a key to living safer, healthier, and longer lives.

The questionnaire provides science teachers with the ability to question themselves about safety issues in their laboratory/ science classrooms. The objective is for teachers to learn to better care about students' health and safety, recognize hazards, protect students, and create a safer and healthier learning and working environment. The questions can be effective to make a significant contribution to achieving these goals and objectives. The outcomes of the study can be helpful to redesign the educational materials, modules, and policies for improving new and update laboratory conditions at schools.

\section{REFERENCES}

Aydoğdu, C., \& Yardımcı, E. (2013). Accidents occured in elementary science laboratories and teachers' behaviour manners toward these accidents. Hacettepe University Journal of Education, 44, 52-60.

Balc1, A. (2007). Sosyal Bilimlerde Araştırma Yöntem, Teknik ve İlkeler. Ankara: Pegem Yayınc1lik.

Büyüköztürk, Ş. (2003). Veri Analizi el Kitabı. (2. bs). Ankara: Pegem a Yayıncilik.

Doğan, T. (2010). Adaptation of the social appearance anxiety scale (saas) to Turkish: A valid and reliability study. Hacettepe University Journal of Education, 39, 151-159.

Downs, G.E., \& Gerlovich, J.L. (1983). Science Safety for Elementary Teachers. Ames, Iowa: The Iowa State University Press.

Engs, R.C. (1996). Construct validity and re-assessment of the reliability of the health concern questionnaire. In: Feldman, R.H.L., Humphrey, J.H., (Eds.), Advances in Health Education/Current Research. Vol. 4. New York: AMS, Press, Inc. pp. 303-313.

Field, A. (2000). Discovering Statistics Using SPSS for Windows. London: Thousand Oaks.

Greco, L.D., Walop, W., McCarthy, R.H. (1987). Questionnaire development: 2. Validity and reliability. Canadian Medical Association Journal, 136, 699-700.

Johanson, G.A., \& Brooks G.P. (2009). Initial scale development: Sample size for pilot studies. Educational and Psychological Measurement, 70(3), 394-400.

Pallant, J. (2005). SPSS Survival Manuel: A Step by Step Guide to Data. Australia: Ligare.

Pavlova, D., \& Kouzov, O. (2016). Unchain the Education Through Mobility, UNESCO International Workshop: QED'16: Technology Advanced Quality Learning for ALL, Za Bukvite, O'Pismeneh Sofia.

Tabachnick, B.G., \& Fidell, L.S. (2001). Using Multivariate Statistics. New York: Harper Collins.

Treece, E.W., \& Treece, J.W. (1982). Elements of Research in Nursing. $3^{\text {rd }}$ ed. St. Louis, MO: Mosby.

Turanli, N.N., Turker, K., \& Keceli, V. (2008). Develeoping an attitude scale for courses in mathematics. Hacettepe University Journal of Education, 34, 254-262.

Yükseköğretim Kurulu and Bilgi Yönetimi Sistemi (TÜİK). (2014). Yükseköğretim İstatistikleri. Available from: https://www.istatistik.yok. gov.tr/yuksekogretimIstatistikleri/2014/2014_3.pdf. [Last accessed on 2017 Sep 19]. 


\section{APPENDIX}

\begin{tabular}{|c|c|c|c|c|}
\hline \multicolumn{5}{|c|}{ Appendix Table 1: Laboratory safety questionnaire } \\
\hline \multirow[t]{2}{*}{ Item } & SD & D & A & SA \\
\hline & 1 & 2 & 3 & 4 \\
\hline
\end{tabular}

I always take care the laboratory is clean and tidy

I know precautions to be taken in case of a fire in laboratory

I know precautions to be taken in case of spills and splashes of chemicals

I know which emergency kits have to be in a laboratory for using in case of an emergency situation

I know the phone numbers to call in an emergency situation

I have information about the health status of my students

I know how should be the standards of an ideal laboratory for schools

I know how to use the ventilation system

I know how to use electrical and lighting in laboratory

I know how to use water system in laboratory

I know how to use gas installations

I know how to use fire extinguisher in case of a fire

I know how to use bucket of sand in case of a fire

I know how to use fire blanket in case of a fire

I know how to design the desks for the students in the laboratory

I know the needs and uses of an emergency exit plan

I know how to use first aid kits in laboratory

I know how to store and keep solid chemicals

I always take care about the shelves are firmly attached to the wall

I always take care all shelves have the protection sets in front sides

I know how to store and keep the liquid chemicals

I know how to store chemicals which need to have special conditions

I work with an inventory which has the identifications of all chemicals in the laboratory

Removed item

I always wear apron during the activities in laboratory

I know what should be done in case of bleeding

I know how to respond in case of a burn, which occurs with contact to hot objects

I know what should be done if any chemicals splash to the eyes

I know how to intervene if need occurs in case of ingestion of any chemicals

I know how to intervene if need occurs with inhalation of chemicals

I know how to intervene in the accident that occurred as a result of electric current

I never leave the laboratory before checking the gas installations

I never leave the laboratory before checking all electrical devices

I never leave the laboratory before checking water system

I labeled the remaining material and get stored in an appropriate manner after the activities

I always take care about to put laboratory materials to the right places after using

I get students to wash their hands and face with water after the activities 